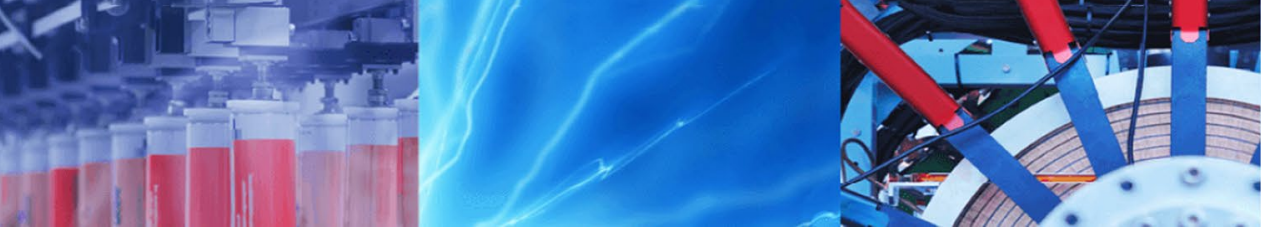

Research Article

\title{
Zirconium chloride molecular species: combining electron impact mass spectrometry and first principles calculations
}

\author{
Rosendo Borjas Nevarez ${ }^{1}$ [D $\cdot$ Eunja Kim ${ }^{2} \cdot$ Bradley C. Childs $^{3} \cdot$ Henrik Braband $^{3} \cdot$ Laurent Bigler $^{3} \cdot$ Urs Stalder $^{3}$. \\ Roger Alberto $^{3}$. Philippe F. Weck ${ }^{4}$. Frederic Poineau ${ }^{1}$
}

(c) Springer Nature Switzerland AG 2019

\begin{abstract}
Zirconium tetrachloride was synthesized from the reaction between zirconium metal and chlorine gas at $300^{\circ} \mathrm{C}$ and was analyzed by electron impact mass spectrometry (El-MS). Substantial fragmentation products of $\mathrm{ZrCl}_{4}$ were observed in the mass spectra, with $\mathrm{ZrCl}_{3}$ being the most abundant species, followed by $\mathrm{ZrCl}_{2}, \mathrm{ZrCl}$, and $\mathrm{Zr}$. The predicted geometry and kinetic stability of the fragments previously mentioned were investigated by density functional theory (DFT) calculations. Energetics of the dissociation processes support the most stable fragment to be $\mathrm{ZrCl}_{3}$ while the least abundant are $\mathrm{ZrCl}$ and $\mathrm{ZrCl}_{2}$.
\end{abstract}

Keywords Zirconium · Chloride - Mass spectrometry - Gas phase · DFT

\section{Introduction}

Zirconium chloride is of crucial importance in numerous research fields and industrial applications such as unconventional catalysis [1], refining of $\mathrm{Zr}$-containing ores by Kroll reduction [2], chemical vapor deposition [3], and nuclear engineering [4-6]. Chlorination has been proposed for large-scale separation and selective recovery of $\mathrm{Zr}$ as $\mathrm{ZrCl}_{4}$ from $\mathrm{U}-\mathrm{Zr}$ alloys or used nuclear fuel cladding $[4,5]$. Due to the presence of impurities (e.g., Sn, Cr, Fe, etc.) in the recovered $\mathrm{ZrCl}_{4}$, further efforts are necessary to improve the purification process. This requires fundamental understanding of the materials during each stage of the process. Starting materials consist of $\mathrm{Zr}$ cladding such as Zircaloy-4, Zircaloy-2 and Zr-Nb alloys (Zirlo ${ }^{\mathrm{TM}}$ and $\mathrm{Zr}-2.5 \mathrm{Nb}$ ) while the final product should be $\mathrm{Zr}$ metal. In the chlorination process, the intermediate material is $\mathrm{ZrCl}_{4}$. Our previous efforts have been devoted on fundamental studies of the starting materials described above
[7], followed by $\mathrm{ZrCl}_{4}[8,9]$. Therefore, an accurate knowledge of zirconium chlorides is crucial for efficient separation and selective recovery of $\mathrm{Zr}$ from cladding materials. While much attention has been given to the theoretical and experimental investigations of crystalline $\mathrm{ZrCl}_{4}$ [9], accurate structural and thermomechanical information of $\mathrm{ZrCl}_{\mathrm{x}}(\mathrm{x}=1,2,3,4)$ molecular species remains scarce. Due to their chemical similarities and the importance of the refinement process in the nuclear industry, studies on gaseous $\mathrm{ZrCl}_{4}$ are typically performed in conjunction with $\mathrm{HfCl}_{4}$. The first electronographic approximations calculated the theoretical intensity curves based on the intermolecular distances in $\mathrm{ZrCl}_{4}$ (i.e. $\mathrm{Zr}-\mathrm{Cl}=2.32 \AA$ and $\mathrm{Cl} \ldots \mathrm{Cl}=3.79 \AA$ ) and in $\mathrm{HfCl}_{4}$ (i.e. $\mathrm{Hf}-\mathrm{Cl}=2.33 \AA$ and $\mathrm{Cl} \ldots \mathrm{Cl}=3.80 \AA$ ) [10]. Recently, Barnes et al. reported that the vapor pressure of $\mathrm{ZrCl}_{4}, \mathrm{FeCl}_{3}, \mathrm{CrCl}_{4}, \mathrm{NbCl}_{5}$, and $\mathrm{NbOCl}_{3}$ are very similar at temperatures near $330^{\circ} \mathrm{C}[11]$. The vapor pressure of $\mathrm{ZrCl}_{4}$ has also been measured under vacuum and under argon atmospheres [12]. In addition, DFT models have been used

$\square$ Rosendo Borjas Nevarez, borjasr@unlv.nevada.edu | ${ }^{1}$ Department of Chemistry and Biochemistry, University of Nevada, Las Vegas, 4505 S. Maryland Pkwy, Las Vegas, NV 89154, USA. ²Department of Physics and Astronomy, University of Nevada, Las Vegas, 4505 S. Maryland Pkwy, Las Vegas, NV 89154, USA. ${ }^{3}$ Department of Chemistry, University of Zurich, Rämistrasse 71, 8006 Zurich, Switzerland. ${ }^{4}$ Sandia National Laboratories, Albuquerque, NM 87185, USA.

SN Applied Sciences (2019) 1:392 | https://doi.org/10.1007/s42452-019-0410-y 
to predict the volatility and adsorption enthalpies of $\mathrm{ZrCl}_{4}$ $\mathrm{ZrOCl}_{2}$, and $\mathrm{ZrCl}_{6}{ }^{2-}$ salts in comparison to the other Group IV metal chlorides. These models are for the most part in disagreement with experimental data [13], demonstrating the complexity of these gas phase interactions. As for gaseous $\mathrm{ZrCl}_{2}$, the structure, vibrational frequencies, and heat of formation have been predicted, and they are in close agreement with experimental data [14].

In this study, we have carried out combined experimental and computational studies to investigate the structures, electronic properties, and relative stability of the $\mathrm{ZrCl}_{x}(x=1,2,3,4)$ molecules in the gas phase.

\section{Experimental}

\subsection{Preparation of sample}

Zirconium metal sponge ( $>99 \%$ purity), and a lecture bottle of chlorine gas ( $>99.5 \%$ purity) were obtained from Sigma Aldrich and used as received. The clamshell furnace was a Lindberg Blue M Mini-Mite.

$\mathrm{ZrCl}_{4}$ was synthesized from the reaction of zirconium metal and chlorine gas at $300^{\circ} \mathrm{C}$ in a glass sealed tube according to the method reported in the literature [9]. After the reaction, the end of the tube containing $\mathrm{ZrCl}_{4}$ was placed in liquid nitrogen and the tube was sealed to separate the zirconium oxide impurity. The capillary was then checked for external contamination and sent to the University of Zurich.

\subsection{Analysis of sample}

At the University of Zurich, the sealed tube was stored in an inert atmosphere $\left(\mathrm{N}_{2}\right)$ glove box. The tube was opened in the glovebox and $\mathrm{ZrCl}_{4}$ samples were placed in sample holders. The samples were then transferred to a Schlenk flask and sealed. The sample was introduced into a glove bag system, which was installed in front of the mass spectrometer and included the sample inlet. The system was evacuated and then purged with argon three times before opening the Schlenk flask. The $\mathrm{ZrCl}_{4}$ sample was mounted on the probe, which was then inserted into the mass spectrometer to be measured. Mass spectrometry measurements were performed on a Thermo DFS (ThermoFisher Scientific, Bremen, Germany) double-focusing magnetic sector mass spectrometer (geometry BE). Mass spectra were measured in electron impact mode at $70 \mathrm{eV}$, with a solid probe inlet, source temperature of $50{ }^{\circ} \mathrm{C}$, acceleration voltage of $5 \mathrm{kV}$, and a resolution of 7000 . The instrument was scanned from $\mathrm{m} / \mathrm{z}=30$ to 800 at a scan rate of $2 \mathrm{~s}$ per decade in the magnetic scan mode, and temperature ramp rate was $60^{\circ} \mathrm{C}$ per minute until $400^{\circ} \mathrm{C}$ was reached.
Perfluorokerosene (PFK, Fluorochem, Derbyshire, UK) was used for mass calibration.

\subsection{Computational method}

First-principles all-electron calculations of the total energies and optimized geometries were performed using the density functional theory (DFT) as implemented in the $\mathrm{DMol}^{3}$ software [15]. The exchange correlation energy was calculated using the generalized gradient approximation (GGA) with the parametrization of Perdew and Wang [16] (PW91). Double numerical basis sets including polarization functions on all atoms (DNP) were used in the calculations. The DNP basis set is comparable to 6-31G** Gaussian basis sets. In the generation of the numerical basis sets, a global orbital cutoff of $3.7 \AA$ was used. The energy tolerance in the self-consistent field calculations was set to $10^{-6}$ Hartree. Optimized geometries were obtained without symmetry constraints using an energy convergence tolerance of $10^{-5}$ Hartree and a gradient convergence of $2 \times 10^{-3}$ Hartree/Å.

\section{Results and discussion}

\subsection{Electron impact mass spectrometry}

Zirconium chloride species yield El-MS peaks that are recognized not only by their mass to charge ratio, but also by their unique splitting pattern due to the isotopic abundances of $\mathrm{Zr}$ and $\mathrm{Cl}$ (Table 1). The spectrum after a retention time of $6.86 \mathrm{~min}\left(400{ }^{\circ} \mathrm{C}\right)$ is presented in Fig. 1. The relative abundances of the observed species were determined from the sum of all the peak counts in the isotopic mass range. In addition to the parent $\mathrm{ZrCl}_{4}$ molecule, the following fragments are present in a quantifiable manner:

Table 1 Splitting of a $\mathrm{ZrCl}_{4}$ peak from $\mathrm{m} / \mathrm{z}=229.8$ to $\mathrm{m} / \mathrm{z}=239.8$ due to isotopic abundance

\begin{tabular}{|c|c|c|c|c|c|}
\hline \multirow{2}{*}{$\frac{\mathrm{m} / \mathrm{z}}{229.8}$} & \multicolumn{5}{|c|}{ Isotopic distribution } \\
\hline & & ${ }^{90} \mathrm{Zr}^{35} \mathrm{Cl}_{4}$ & & & \\
\hline 230.8 & & ${ }^{91} \mathrm{Zr}^{35} \mathrm{Cl}_{4}$ & & & \\
\hline 231.8 & ${ }^{90} \mathrm{Zr}^{35} \mathrm{Cl}_{3}^{37} \mathrm{Cl}$ & ${ }^{92} \mathrm{Zr}^{35} \mathrm{Cl}_{4}$ & & & \\
\hline 232.8 & ${ }^{91} \mathrm{Zr}^{35} \mathrm{Cl}_{3}^{37} \mathrm{Cl}$ & & & & \\
\hline 233.8 & ${ }^{92} \mathrm{Zr}^{35} \mathrm{Cl}_{3}^{37} \mathrm{Cl}$ & ${ }^{94} \mathrm{Zr}^{35} \mathrm{Cl}_{4}$ & ${ }^{90} \mathrm{Zr}^{35} \mathrm{Cl}_{2}^{37} \mathrm{Cl}_{2}$ & & \\
\hline 234.8 & & & ${ }^{91} \mathrm{Zr}^{35} \mathrm{Cl}_{2}^{37} \mathrm{Cl}_{2}$ & & \\
\hline 235.8 & ${ }^{94} \mathrm{Zr}^{35} \mathrm{Cl}_{3}^{37} \mathrm{Cl}$ & ${ }^{96} \mathrm{Zr}^{35} \mathrm{Cl}_{4}$ & ${ }^{92} \mathrm{Zr}^{35} \mathrm{Cl}_{2}^{37} \mathrm{Cl}_{2}$ & ${ }^{90} \mathrm{Zr}^{35} \mathrm{Cl}^{37} \mathrm{Cl}_{2}$ & \\
\hline 236.8 & & & & ${ }^{91} \mathrm{Zr}^{35} \mathrm{Cl}^{37} \mathrm{Cl}_{3}$ & \\
\hline 237.8 & ${ }^{96} \mathrm{Zr}^{35} \mathrm{Cl}_{3}^{37} \mathrm{Cl}$ & & ${ }^{94} \mathrm{Zr}^{35} \mathrm{Cl}_{2}^{37} \mathrm{Cl}_{2}$ & ${ }^{92} \mathrm{Zr}^{35} \mathrm{Cl}^{37} \mathrm{Cl}_{3}$ & ${ }^{90} \mathrm{Zr}^{37} \mathrm{Cl}_{4}$ \\
\hline 238.8 & & & & & ${ }^{91} \mathrm{Zr}^{37} \mathrm{Cl}_{4}$ \\
\hline 239.8 & & & ${ }^{96} \mathrm{Zr}^{35} \mathrm{Cl}_{2}^{37} \mathrm{Cl}_{2}$ & ${ }^{94} \mathrm{Zr}^{35} \mathrm{Cl}^{37} \mathrm{Cl}_{3}$ & ${ }^{92} \mathrm{Zr}^{37} \mathrm{Cl}_{4}$ \\
\hline
\end{tabular}




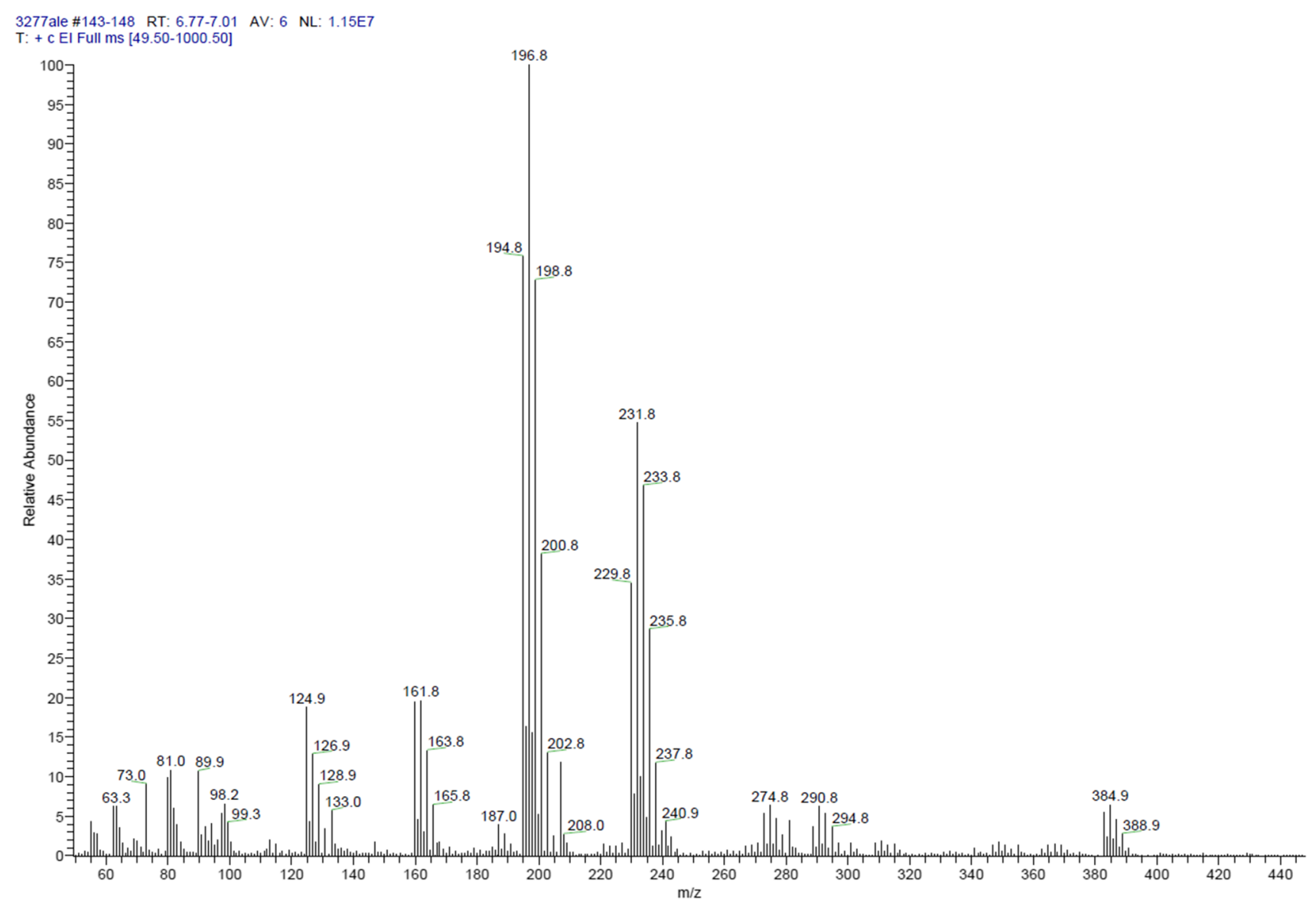

Fig. 1 Electron impact mass spectra $(70 \mathrm{eV})$ of $\mathrm{ZrCl}_{4}$ between $\mathrm{m} / \mathrm{z}=50$ and $\mathrm{m} / \mathrm{z}=440$

Table 2 Relative abundance of zirconium chloride fragments in the El-MS spectra of $\mathrm{ZrCl}_{4}$

\begin{tabular}{llll}
\hline Peak range $(\mathrm{m} / \mathrm{z})$ & Molecule & Intensity & $\begin{array}{l}\text { Abundance } \\
\text { (normalized) } \\
(\%)\end{array}$ \\
\hline 89.9 & $\mathrm{Zr}^{+}$ & $1,228,923.2$ & 1.92 \\
$97.2-99.3$ & $\mathrm{ZrCl}_{3}{ }^{++}$ & $1,836,960.4$ & 2.87 \\
$124.9-128.9$ & $\mathrm{ZrCl}^{+}$ & $5,168,760.7$ & 8.09 \\
$159.8-165.8$ & $\mathrm{ZrCl}_{2}^{+}$ & $7,295,977.8$ & 11.4 \\
$194.8-202.8$ & $\mathrm{ZrCl}_{3}^{+}$ & $25,427,641.7$ & 39.8 \\
$229.8-239.8$ & $\mathrm{ZrCl}_{4}^{+}$ & $22,938,047.9$ & 35.9 \\
Total & & $63,896,311.7$ & 100 \\
\hline
\end{tabular}

$\mathrm{ZrCl}_{3}{ }^{+}, \mathrm{ZrCl}_{3}{ }^{2+}, \mathrm{ZrCl}_{2}{ }^{+}, \mathrm{ZrCl}^{+}$, and $\mathrm{Zr}^{+}$(Table 2), with $\mathrm{ZrCl}_{3}$ clearly as the most abundant species. It is noted that $\mathrm{ZrCl}_{3}$ is also found in the separation of $\mathrm{HfCl}_{4}$ from $\mathrm{ZrCl}_{4}$ using molten salts [17]. The presence of $\mathrm{ZrCl}_{4}{ }^{2+}, \mathrm{ZrCl}_{2}{ }^{2+}$, and $\mathrm{ZrCl}^{2+}$ is also noticed in the El-MS spectra of $\mathrm{ZrCl}_{4}$ while the dimeric species $\mathrm{Zr}_{2} \mathrm{Cl}_{7}{ }^{+}$(m/z 425) [18] could not be identified in our experimental conditions.
A previous El-MS study on $\mathrm{ZrCl}_{4}$ by Schäfer detected the fragments: $\mathrm{ZrCl}_{3}{ }^{2+}, \mathrm{Zr}^{+}, \mathrm{ZrCl}^{+}, \mathrm{ZrCl}_{2}{ }^{+}, \mathrm{ZrCl}_{3}{ }^{+}$, and $\mathrm{Zr}_{2} \mathrm{Cl}_{7}{ }^{+}$. Also, the mass spectra revealed dimerization of $\mathrm{ZrCl}_{4}$ to $\left(\mathrm{ZrCl}_{4}\right)_{2}^{+}$with a $\left(\mathrm{ZrCl}_{4}\right)_{2}^{+} / \mathrm{ZrCl}_{4}{ }^{+}$ratio of 0.000401 at $459 \mathrm{~K}$ [18]. Our data supports the favorable formation of the lower mass fragments. Interestingly, fragments with $\mathrm{m} / \mathrm{z}$ ratios higher than the mass of $\mathrm{ZrCl}_{4}$ are also observed at $\mathrm{m} / \mathrm{z} \sim 385$ but those ratios do not agree with any of the previous findings or with the sum of any combination of $\mathrm{Zr}$ and $\mathrm{Cl}$ atomic masses.

\subsection{Computational studies}

Systematic studies to investigate the stable geometries of the neutral and ionic $\mathrm{ZrCl}_{\mathrm{x}}$ species has been carried out using density-functional theory (DFT), as implemented in $\mathrm{Dmol}^{3}$ [17] within the level of DFT-PW91 [16], as summarized in Fig. 2. The theoretically optimized geometries indicate that $\mathrm{ZrCl}$ is a linear molecule with $\mathrm{Zr}-\mathrm{Cl}=2.37 \AA$. It is worth noting that the predicted $\mathrm{ZrCl}_{2}$ is in $\mathrm{C} 2 \mathrm{v}$ with an average $\mathrm{Zr}-\mathrm{Cl}=2.38 \AA$. The optimized structure of $\mathrm{ZrCl}_{3}$ is planar in $\mathrm{C} 3 \mathrm{v}$ with $\mathrm{Zr}-\mathrm{Cl}=2.35 \AA$. The gaseous 


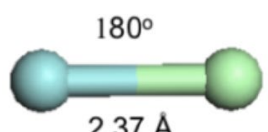

$2.37 \AA$

(a) $\mathrm{ZrCl}$

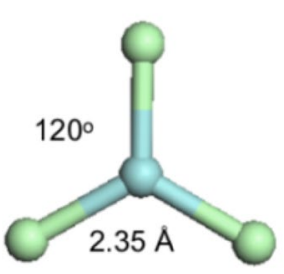

(c) $\mathrm{ZrCl}_{3}$ (b) $\mathrm{ZrCl}_{2}$

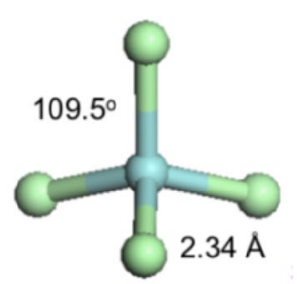

(d) $\mathrm{ZrCl}_{4}$

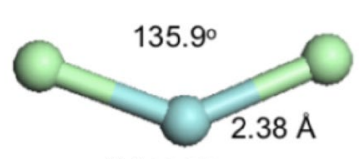

Fig. 2 Ball and stick models of theoretically optimized $\mathrm{ZrCl}_{x}$ molecules: a $\mathrm{ZrCl}, \mathbf{b} \mathrm{ZrCl}_{2}, \mathbf{c} \mathrm{ZrCl}_{3}$, and $\mathbf{d} \mathrm{ZrCl}_{4}$. Cyan and green spheres represent $\mathrm{Zr}$ and $\mathrm{Cl}$ atoms, respectively

$\mathrm{ZrCl}_{4}$ is stabilized in the tetrahedral $\left(\mathrm{T}_{\mathrm{d}}\right)$ structure with $\mathrm{Zr}-\mathrm{Cl}=2.34 \AA$, which is nearly identical to the $2.32 \AA$ and $2.33 \AA$ previously reported for $\mathrm{ZrCl}_{4}$ and $\mathrm{HfCl}_{4}$ [10]. The $\mathrm{Zr}-\mathrm{Cl}$ bond distances of the respective ionic forms are slightly shorter, $2.29 \AA\left(\mathrm{ZrCl}^{+}\right), 2.30 \AA\left(\mathrm{ZrCl}_{2}^{+}\right), 2.32 \AA$ $\left(\mathrm{ZrCl}_{3}{ }^{+}\right)$, and $2.36 \AA\left(\mathrm{ZrCl}_{4}{ }^{+}\right)$, decreasing by no more than $0.08 \AA$ with respect to the neutral species. The most noticeable change in geometry occurs in the $\mathrm{ZrCl}_{2}$ bond angle, $135.9^{\circ}$ in the neutral form and $110^{\circ}$ in the ionic form.

The kinetic stability of these $\mathrm{ZrCl}_{\mathrm{x}}$ species was evaluated in terms of the energy gap between the highest occupied molecular orbitals (HOMO) and lowest unoccupied molecular orbitals (LUMO). The calculated HOMO and LUMO for $\mathrm{ZrCl}_{\mathrm{x}}$ are presented in Fig. 3. The top and bottom panels depict the HOMO and LUMO of the molecules, respectively, indicating that the major contribution to $\mathrm{HOMO}$ of $\mathrm{ZrCl}_{2}, \mathrm{ZrCl}_{3}$, and $\mathrm{ZrCl}_{4}$ is from $\mathrm{Cl}$-p orbitals while its counterpart to LUMO is mainly from $\mathrm{Zr}$-d orbitals.

The calculated HOMO-LUMO gaps are $0.46 \mathrm{eV}(\mathrm{ZrCl})$, $3.84 \mathrm{eV}\left(\mathrm{ZrCl}_{2}\right), 3.53 \mathrm{eV}\left(\mathrm{ZrCl}_{3}\right)$, and $4.35 \mathrm{eV}\left(\mathrm{ZrCl}_{4}\right)$, suggesting $\mathrm{ZrCl}_{4}$ to be the most stable species and $\mathrm{ZrCl}$ the least stable species. The HOMO-LUMO gaps of the corresponding ionic species are $3.98 \mathrm{eV}\left(\mathrm{ZrCl}^{+}\right), 3.44 \mathrm{eV}\left(\mathrm{ZrCl}_{2}^{+}\right)$, $3.21 \mathrm{eV}\left(\mathrm{ZrCl}_{3}{ }^{+}\right)$, and $4.39 \mathrm{eV}\left(\mathrm{ZrCl}_{4}{ }^{+}\right)$, respectively. A substantial amount of charge transfer from $\mathrm{Zr}$ to $\mathrm{Cl}$ occurs in these molecular species, 0.47e $(\mathrm{ZrCl}), 0.47 \mathrm{e}\left(\mathrm{ZrCl}_{2}\right), 0.43 \mathrm{e}$ $\left(\mathrm{ZrCl}_{3}\right)$, and $0.36 \mathrm{e}\left(\mathrm{ZrCl}_{4}\right)$. Charge transfer of the corresponding ionic species is estimated to be $0.26 \mathrm{e}\left(\mathrm{ZrCl}^{+}\right)$, $0.23 \mathrm{e}\left(\mathrm{ZrCl}_{2}^{+}\right), 0.21 \mathrm{e}\left(\mathrm{ZrCl}_{3}^{+}\right)$, and $0.13 \mathrm{e}\left(\mathrm{ZrCl}_{4}^{+}\right)$. The difference in charge transfer shows that $\mathrm{Zr}-\mathrm{Cl}$ bonds are stronger in the neutral species. The calculated structural data and energetics of neutral and ionic $\mathrm{ZrCl}_{\mathrm{x}}$ molecules are summarized in Table 3.
Fig. 3 The calculated highest occupied molecular orbitals (HOMO, top) and lowest unoccupied molecular orbitals (LUMO, bottom) of $\mathbf{a} \mathrm{ZrCl}, \mathbf{b}$ $\mathrm{ZrCl}_{2}, \mathbf{c} \mathrm{ZrCl}_{3}$, and $\mathbf{d ~} \mathrm{ZrCl}_{4}$
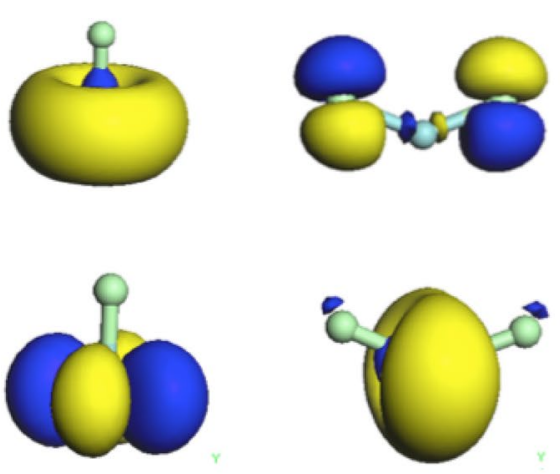

(a) $\mathrm{ZrCl}$
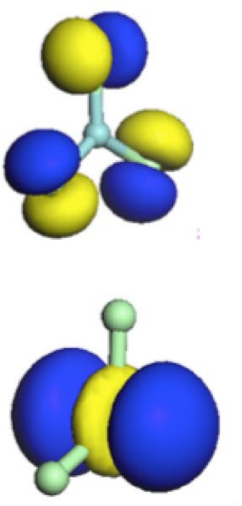

(c) $\mathrm{ZrCl}_{3}$
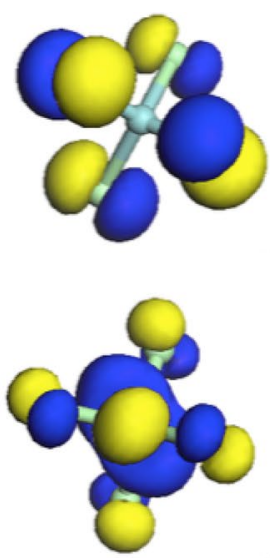

(d) $\mathrm{ZrCl}_{4}$
Table 3 Calculated $\mathrm{Zr}$-Cl distance $(\AA ̊ \cap)$, bond angle $\left({ }^{\circ}\right)$, charge transfer (e) and HOMOLUMO gap (eV) for $\mathrm{ZrCl}, \mathrm{ZrCl}_{2}$, $\mathrm{ZrCl}_{3}, \mathrm{ZrCl}_{4}$ molecular and the corresponding ionic species. The value in the parenthesis is from Ref [13]

\begin{tabular}{|c|c|c|c|c|c|c|c|c|}
\hline & \multicolumn{4}{|c|}{ Neutral species } & \multicolumn{4}{|c|}{ Ionic species } \\
\hline & $\mathrm{ZrCl}$ & $\mathrm{ZrCl}_{2}$ & $\mathrm{ZrCl}_{3}$ & $\mathrm{ZrCl}_{4}$ & $\mathrm{ZrCl}^{+}$ & $\mathrm{ZrCl}_{2}^{+}$ & $\mathrm{ZrCl}_{3}^{+}$ & $\mathrm{ZrCl}_{4}^{+}$ \\
\hline $\mathrm{Zr}-\mathrm{Cl}$ distance $(\AA ̊)$ & 2.37 & 2.38 & 2.35 & $2.34(2.336)$ & 2.29 & 2.30 & 2.32 & 2.36 \\
\hline Bond angle $\left({ }^{\circ}\right)$ & 180 & 135.9 & 120 & 109 & 180 & 110 & 120 & 109 \\
\hline HOMO-LUMO gap (eV) & 0.46 & 3.84 & 3.53 & 4.35 & 3.98 & 3.44 & 3.21 & 4.39 \\
\hline Charge transfer from $\mathrm{Zr}$ to $\mathrm{Cl}(e)$ & 0.47 & 0.47 & 0.43 & 0.36 & 0.26 & 0.23 & 0.21 & 0.13 \\
\hline
\end{tabular}


The El-MS measurements provide a clear evidence of monochloride, dichloride, trichloride in the gas phase which are due to the fragmentation of $\mathrm{ZrCl}_{4}$. The absence of $\mathrm{Zr}_{2} \mathrm{Cl}_{7}^{+}$in the gas phase might be due to the instability of this species in our experimental conditions. Therefore, the dissociation scenario of $\mathrm{ZrCl}_{4}$ into the lower chloride species has been investigated as follows.

(1) $2 \mathrm{ZrCl}_{4} \rightarrow 2 \mathrm{ZrCl}_{3}+1 \mathrm{Cl}{ }_{2}, \Delta \mathrm{E}=3.44 \mathrm{eV} / \mathrm{Cl}$;

(2) $2 \mathrm{ZrCl}_{4} \rightarrow 2 \mathrm{ZrCl}_{2}+2 \mathrm{Cl}_{2}, \Delta \mathrm{E}=3.71 \mathrm{eV} / \mathrm{Cl}$;

(3) $2 \mathrm{ZrCl}_{4} \rightarrow 2 \mathrm{ZrCl}+3 \mathrm{Cl}_{2}, \Delta \mathrm{E}=3.81 \mathrm{eV} / \mathrm{Cl}$.

It is found that the dissociation cost of $\mathrm{ZrCl}_{4}$ to $\mathrm{ZrCl}_{3}$ is $\sim 3.44 \mathrm{eV} / \mathrm{Cl}$ while the dissociation cost to produce $\mathrm{ZrCl}_{2}$ and $\mathrm{ZrCl}$ are, respectively, 3.71 and $3.81 \mathrm{eV} / \mathrm{Cl}$. These results indicate that the formation of $\mathrm{ZrCl}$ and $\mathrm{ZrCl}_{2}$ are the most energetically expensive and that those species are not as abundant as $\mathrm{ZrCl}_{3}$ in the gas phase.

\section{Conclusions}

In summary, $\mathrm{ZrCl}_{4}$ was synthesized from the thermal reaction between zirconium metal and chlorine gas and analyzed by EI-MS. The EI-MS results indicate the presence of $\mathrm{ZrCl}_{4}^{+}, \mathrm{ZrCl}_{3}^{+}, \mathrm{ZrCl}_{2}^{+}$and $\mathrm{ZrCl}^{+}$in the gas phase. The abundance of $\mathrm{ZrCl}_{4}$ fragments in the gas phase follow the order $\mathrm{ZrCl}_{3}{ }^{+} \gg \mathrm{ZrCl}_{2}^{+} \sim \mathrm{ZrCl}^{+}$. Previously reported dimeric species (i.e., $\mathrm{Zr}_{2} \mathrm{Cl}_{7}$ ) [18] have not been observed in our experimental conditions.

The structure and energetics of neutral and ionic $\mathrm{ZrCl}_{\mathrm{x}}$ $(x=1,2,3,4)$ in the gas phase were investigated by DFT methods. The studies of both neutral and ionic species are of interest in the zirconium cladding purification process to explain the formation of ternary compounds, such as $\mathrm{ZrFeCl}_{6}[19]$, observed in the gas phase. The process by which these intermediate ternary compounds are formed is not well understood, and it could involve both neutral and ionic forms of the chlorides due to molecular collisions at high temperatures. The calculated structural parameters are well in agreement with the one found in the literature. Calculations indicate the energy cost to produce $\mathrm{ZrCl}_{2}$ and $\mathrm{ZrCl}$ fragments is higher than the one to produce $\mathrm{ZrCl}_{3}$ which gives a rational explanation to the large abundance of $\mathrm{ZrCl}_{3}$ in the gas phase during El-MS. The high stability of $\mathrm{ZrCl}_{3}$ in the gas phase indicates that this species could be used in volatility based separation of $\mathrm{Zr}$ cladding. For example, the $\mathrm{Zr}$ cladding could be initially chlorinated, the resulting chloride species $\left(\mathrm{ZrCl}_{4}\right.$, metal chloride impurity) would be reduced with hydrogen and the resulting $\mathrm{ZrCl}_{3}$ separated from the chloride impurity after thermal treatment. Similarly, $\mathrm{ZrCl}_{3}$ could be the species that reacts with $\mathrm{FeCl}_{3}$ to form dimeric species, and therefore making iron a difficult impurity to remove. Current works are in progress in our laboratory to develop a process based on purification of $\mathrm{Zr}$ cladding involving $\mathrm{ZrCl}_{3}$.

Funding This research was performed using funding received from the U.S. Department of Energy, Office of Nuclear Energy's Nuclear Energy University Program (NEUP) (Grant No. DE-NE0008449). Sandia National Laboratories is a multi-mission laboratory managed and operated by National Technology and Engineering Solutions of Sandia, LLC., a wholly owned subsidiary of Honeywell International, Inc., for the U.S. Department of Energy's National Nuclear Security Administration under Contract DE-NA0003525. The views expressed in the article do not necessarily represent the views of the U.S. DOE or the United States Government.

\section{Compliance with ethical standards}

Conflict of interest The authors declare that they have no conflict of interest.

\section{References}

1. Homerin G, Baudelet $D$, Dufrénoy $P$, Rigo B, Lipka $E$, Dezitter $X$, Furman C, Millet $\mathrm{R}$, Ghinet $\mathrm{A}$ (2016) $\mathrm{ZrCl}_{4}$ as a new catalyst for ester amidation: an efficient synthesis of $h-P 2 X 7 R$ antagonists. Tetrahedron Lett 57:1165-1170

2. Lustman B, Kerze JF (1955) The metallurgy of zirconium. Mc Graw Hill, New York

3. Van der Vis MGM, Cordfunke EHP, Konings RJM (1997) Thermochemical properties of zirconium halides: a review. Thermochim Acta 302:93-108

4. Bohe AE, Andrade Gamboa JJ, Pasquevich DM (1997) Chlorination process applied to zirconium recovery from zircaloy shavings. Mater Sci Technol 13(10):865-871

5. Collins ED, DelCul GD, Spencer BB, Brunson RR, Johnson JA, Terekhov DS, Emmanuel NV (2012) Process development studies for zirnonium recovery/recycle from used nuclear fuel cladding. Procedia Chem 7:72-76

6. Ogawa T, Fukuda K, Kashimura S, Tobita T, Kobayashi F, Kado S, Miyanishi H, Takahashi I, Kikuchi T (1992) Performance of ZrCcoated particle fuel in irradiation and postirradiation heating tests. J Am Ceram Soc 75(11):2985-2990

7. Weck PF, Kim E, Tikare V, Mitchell JA (2015) Mechanical properties of zirconium alloys and zirconium hydrides predicted from density functional perturbation theory. Dalton Trans 44:18769-18779

8. Kim E, Weck PF, Borjas R, Poineau F (2018) Lattice dynamics and thermomechanical properties of zirconium(IV) chloride: evidence for low-temperature negative thermal expansion. Chem Phys Lett 691:98-102

9. Borjas Nevarez R, Mariappan Balasekaran S, Kim E, Weck PF, Poineau F (2018) Zirconium tetrachloride revisited. Acta Crystallogr C74(3):307-311

10. Spiridonov VP, Akishin PA, Tsirel'nikov VI (1962) Electronographic investigation of the structure of zirconium and hafnium tetrachloride molecules in the gas phase. Zh Strukt Khim 3(3):329-330

11. Barnes C, Kandziolka M, Ortiz M, McAnly E, DelCul GD, McLaughlin DF (2016) Investigations into the gas phase reactions od zirconium tetrachloride $\left(\mathrm{ZrCl}_{4}\right)$ from UNF cladding. Trans Am Nucl Soc 114:203 
12. Liu C, Liu B, Shao Y, Li Z, Tang C (2008) Vapor pressure and thermochemical properties of $\mathrm{ZrCl}_{4}$ for $\mathrm{ZrC}$ coating of coated fuel particles. Trans Nonferr Met Soc China 18:728-732

13. Pershina V, Borschevsky A, Illias M, Turler A (2014) Theoretical predictions of properties and volatility of chlorides and oxychlorides of group-4 elements. Il. Adsorption of tetrachlorides and oxydichlorides of $\mathrm{Zr}, \mathrm{Hf}$, and $\mathrm{Rf}$ on neutral and modified surfaces. J Chem Phys 1:1. https://doi.org/10.1063/1.4891531

14. Sahan Thanthiriwatte $K$, Vasiliu M, Battey SR, Lu Q, Peterson KA, Andrews L, Dixon DA (2015) Gas phase properties of $M X_{2}$ and $\mathrm{MX}_{4}(\mathrm{X}=\mathrm{F}, \mathrm{Cl})$ for $\mathrm{M}=$ group 4, group 14 , cerium, and thorium. DOI, J Phys Chem A. https://doi.org/10.1021/acs.jpca.5b02544

15. Delley B (2000) From molecules to solids with the $\mathrm{DMol}^{3}$ approach. J Chem Phys. https://doi.org/10.1063/1.1316015
16. Perdew JP, Wang $Y$ (1992) Accurate and simple analytic representation of the electron-gas correlation energy. Phys Rev B 45:13244

17. Kirihara T, Nakagawa I, Seki Y, Honda Y, Ichihara Y (1989) Separation of hafnium tetrachloride from zirconium tetrachloride. FR 2625739, A1

18. Schäfer H, Binnewies M (1974) Die Stabilitat gasformiger dimerer Chloridmolekeln. Z Anorg Allg Chem 410:251-268

19. Troyanov SI, Kharisov BI, Berdonosov SS (1992) Crystal structure of $\mathrm{FeZrCl}_{6}$-a new structural type for $\mathrm{ABX}_{6}$ compounds. $\mathrm{Zh}$ Neorg Khim 37:2424-2429

Publisher's Note Springer Nature remains neutral with regard to jurisdictional claims in published maps and institutional affiliations. 